\title{
APROVEITAMENTO DE BAGAÇO DE MAÇÃ PARA A PRODUÇÃO DE ÁLCOOL E OBTENÇÃO DE FIBRÁS ALIMENTARES
}

\author{
Utilization of apple pomace for ethanol production and food fiber obtainment
}

\author{
Cícero Paganini ${ }^{1}$, Alessandro Nogueira ${ }^{2}$, Nelci Chiquetto Silva ${ }^{3}$, Gilvan Wosiacki $^{3}$
}

\begin{abstract}
RESUMO
A produção brasileira de maçã, cerca de 850 mil toneladas, supre o mercado interno para consumo in natura e o rigor do beneficiamento fez com que as "maçãs industriais" se tornassem expressivas, pois podem atingir 200.000 toneladas na safra 2005/ 2006. Além de sidra e vinagre, é produzido suco clarificado concentrado, o que abre as portas de exportação tanto para outros estados quanto para outros países. O bagaço residual também pode ser aproveitado. Com este trabalho, objetivou-se determinar os parâmetros da extração de açúcar para processos fermentativos e para produção de um resíduo sólido com elevados teores de fibras alimentares. Foram utilizadas maçãs das variedades Fuji, Gala e Golden delicious, as comerciais mais expressivas economicamente, processadas em nível de bancada. O esgotamento dos sólidos solúveis totais com água foi testado utilizando-se como variável independente a razão água (volume) : bagaço (massa) de 0,6:1 a 2:1. O tempo de maceração, de 1 a 10 horas, foi a segunda variável e a terceira, o número de extrações efetuadas.Os parâmetros foram monitorados por análises físico-químicas: sólidos solúveis, açúcares redutores solúveis e totais, compostos fenólicos, acidez total, nitrogênio total, cinzas, matéria seca, lipídeos e minerais. O menor volume de água na extração aumentou a concentração de nutrientes e açúcares no extrato; no caso da razão 0,6:1 após a segunda lavagem o extrato apresentou $10,5^{\circ}$ Brix. Após 5 horas de maceração o rendimento foi $36 \%$ mais elevado, em volume, no primeiro lote, com o mesmo valor em sólidos solúveis totais. A maior extração, de $80 \%$, foi alcançada nas primeiras 3 lavagens (utilizando a mesma água inicial); nas seguintes o aumento foi de $1^{\circ}$ Brix por extração. Com relação às fibras foi observado que quando se utilizava mais água o processo de extração dos sólidos solúveis era mais rápido; a relação $1: 1$ após 4 extrações com água possibilitou que os $6,0^{\circ}$ Brix do bagaço diminuíssem para $1,5^{\circ}$ Brix. Dessa forma, quatro extrações com água foram suficientes para exaurir o bagaço em sólidos solúveis; o extrato apresentou-se com elevados teores de açúcares e nutrientes, propício para a fermentação alcoólica, com interesse especial para pequenos produtores.
\end{abstract}

Termos para indexação: Bagaço de maçã, extrato do bagaço, fibras, fermentação alcoólica, Malus domestica.

\begin{abstract}
Brazilian apple annual production, estimated as 850.000 ton for the current crop, can supply the domestic market as table fruit but the specific technology utilized for selection and classification has as consequence a high amount of the so called «industrial apples», that may reach around 200.000 in the next year (2005/2006). Cider and vinegar are been produced traditionally and nowadays there is an incipient production of clarified concentrate apple juice that may be driven for exportation processes both to other States of Brazil and to another countries. The by-product known as pomace can be utilized for some industrial processing in order to aggregate some economical profits. This article was made aiming to specify some parameter of sugar extraction for fermentation processing as well as to produce a sugar-free apple pomace flour with high content of fiber. In this sense it were utilized samples of the varieties Fuji, Gala e Golden delicious, the most important varieties from the economical point of view, for a laboratory scale processing. The extraction of total soluble solids with water was studied considering as input variable the ratio water (volume) : pomace (mass) from $0,6: 1$ up to $2: 1$. The time, from 1 up to $10 \mathrm{~h}$ was another input variable as well as the number of batch extraction utilized. The success of the operation was monitored by physical and chemical analysis: soluble solids ( ${ }^{\circ}$ Brix), total sugar, phenol compounds, tritatable acidity, total nitrogen, ash, dry mass, lipids and minerals. It was found that when it is used less volume of water the concentration of nutrients specially sugar increases in the extract; for instance, in the essay made with the ratio 0,6:1 just in the second treatment the extract reaches $10,5^{\circ}$ Brix. More than 5 hours in contact made possible a yield $36 \%$ higher than the control, in volume and in the first batch, with the same value in soluble solids. The higher extraction, of $80 \%$, was reached in the first 3 batches, using the same initial water; in the next the increase was around $1^{\circ} \mathrm{Brix}$ each batch. With respect to total fiber it was observed that when it was utilized more water the process required less time; the ratio 1:1, after 4 batches made that the initial $6,0^{\circ}$ Brix from the pomace drop down to $1,5^{\circ}$ Brix. Four water extractions were enough to exhaust the pomace and leaving an extract with a high content in sugar and other soluble nutrient, proper for alcoholic fermentation in a way possible to conduct in small scale.
\end{abstract}

Index terms: pomace, apple, fiber, alcoholic fermentation, Malus domestica.

(Recebido para publicação em 8 de outubro de 2003 e aprovado em 24 de agosto de 2005)

\footnotetext{
${ }^{1}$ Acadêmico de Engenharia de Alimentos, bolsista de Iniciação Científica do CNPq.

${ }^{2}$ Engenheiro Agrônomo, Dr. Processos Biotecnológicos Agroindustriais, Bolsista Recém Doutor do CNPq.

${ }^{3}$ Professores Doutores do Departamento de Engenharia de Alimentos - Setor de Ciências Agrárias e de Tecnologia - Universidade Estadual de Ponta Grossa - Avenida General Carlos Cavalcanti, 4748 - Campus Universitário de Uvaranas - 84.030-970 - Ponta Grossa, PR alessandronog@yahoo.com.br
} 


\section{INTRODUÇÃO}

O processamento de maçãs brasileiras está em sua fase inicial, uma vez que, recentemente, foi atendido o mercado doméstico altamente exigente na qualidade deste produto agrícola.

$\mathrm{Na}$ década de 50, foram instalados os primeiros pomares comerciais no interior de São Paulo (Região Sudeste) que tecnicamente não foram bem-sucedidos devido às características edafoclimáticas, não adequadas às variedades selecionadas para o cultivo. Na década de 70 , foram instalados com sucesso os pomares comerciais nas regiões elevadas dos estados sulinos compreendendo o Sul do Paraná, a Região Serrana de Santa Catarina e a Serra Gaúcha do Norte do Estado do Rio Grande do Sul (WOSIACKI et al., 2000).

Na safra de 2003/2004, o prognóstico atinge o potencial de produção de maçãs da ordem de 850.000 toneladas/ano, o que pode representar aproximadamente 200 mil toneladas de maçãs de descarte, decorrente do rigoroso processo de seleção e classificação comercial utilizada para satisfazer as exigências do consumidor brasileiro. Esse descarte, expurgadas as frutas portadoras de doenças e visivelmente de má qualidade, pode ser utilizado para o processamento e constitui-se na matériaprima disponível para a indústria de transformação (ABPM, 2003; PAGANINI et al., 2004).

O resíduo de extração (bagaço) apresenta-se como o principal subproduto gerado na agroindústria da maçã (HANG, 1987). O resultado dessa extração compreende as cascas e polpa (94,5\%), as sementes $(4,4 \%)$ e os centros $(1,1 \%)$ (KENNEDY et al., 1999). O conteúdo de açúcares totais é elevado, cerca de $40 \%$ em base seca, mas pode apresentar menores teores com alterações no processamento de extração de suco.

A quantidade de bagaço produzida está diretamente relacionada com a tecnologia empregada na extração do suco de maçã que pode representar de $20-40 \%$ do peso das maçãs processadas (STURZA, 1995). Esse sub-produto contém $80 \%$ de umidade, $5 \%$ de fibras (composta por $31 \%$ de celulose, $15 \%$ de lignina, $12 \%$ celulose e $9 \%$ de pectina insolúvel em água) e 14\% de sólidos solúveis dos quais a maioria corresponde a açúcares invertidos, uma mistura de glucose, frutose e sacarose, o que o torna muito susceptível à deterioração por microrganismos e, por esse motivo, a incorreta disposição do material pode acarretar problemas ambientais (CHEN et al., 1988; DOWNING, 1989).

No Brasil, o bagaço é dispensado no solo como adubo orgânico ou utilizado como ração animal, porém a fermentação no rúmem provoca alcolemia, com prejuízos à saúde do gado bovino (KENNEDY et al., 1999; VILLASBOAS \& ESPOSITO, 2001). A literatura descreve aplicações do bagaço que compreendem alimentação animal, modificação e/ou incorporação em alimentos, produção de etanol (fermentação em estado sólido), aromas, gás natural, ácido cítrico, pectinas, enzimas, cogumelos, extração de fibras e carvão vegetal (ALMOSNINO \& BELIN, 1991; BEROVIC \& OSTROVERSNIK, 1997; CHEN et al., 1988; DOWNING, 1989; JEWELL \& CUMMINGS, 1984; KENNEDY et al., 1999; NGADI \& CORREIA, 1992).

O esgotamento desse bagaço, pelo processo de difusão, é utilizado em países europeus para aumentar o rendimento de suco de maçã, porém, o custo é elevado, uma vez que necessita ser clarificado, filtrado e concentrado (GLUNK, 1981). Para efeitos de esgotamento destes açúcares deve-se levar em conta qual a intenção do processo posterior: no caso de fermentação alcoólica há necessidade de agregação mínima de água obtendo-se um extrato com o máximo de sólidos solúveis totais. No caso de se utilizar o bagaço como fonte para extração de pectina ou fibras alimentares deve ser extraído todo sólido solúvel sem levar em conta a água necessária, limitando-se o volume apenas em termos de custos operacionais.

Sendo assim, o extrato do bagaço viabiliza a utilização dos sólidos solúveis em processos fermentativos com produção de álcool ou bebida alcoólica e da obtenção de material fibroso para a extração ácida de pectina ou para uso como volumoso na alimentação animal.

Dessa forma, neste trabalho, propõe-se focalizar o processo de esgotamento de bagaço de maçã no que diz respeito aos teores de sólidos solúveis totais, visando a sua fermentação e por outro, a disponibilidade de um subproduto rico em fibras vegetais a ser estudado em termos de potencial de uso, seja alimentar ou não.

\section{MATERIAL E METODOS}

\section{Material}

As cultivares de maçãs utilizadas foram a Fuji, Gala e Golden, obtidas no comércio local da região de Ponta Grossa - PR, da safra de 2002/2003.

\section{Obtenção do bagaço}

As maçãs foram processadas em nível de bancada, visando a obtenção de suco e de bagaço. As frutas foram lavadas, pesadas, cortadas, trituradas com multiprocessador de pequeno porte (Walita) e prensadas em equipamento hidráulico (Eureka) por 15 minutos a 3

Ciênc. agrotec., Lavras, v. 29, n. 6, p. 1231-1238, nov./dez., 2005 
$\mathrm{Kg} / \mathrm{cm}^{2}$. O suco de maçã foi armazenado após ter sido clarificado, engarrafado e tratado termicamente $80^{\circ} \mathrm{C}$ por 20 minutos. O bagaço de maçã foi utilizado como matériaprima nos experimentos delineados, visando o esgotamento dos sólidos solúveis totais.

\section{Efeito do volume do líquido extrator}

Os experimentos delineados contemplam a extração de várias frações de bagaço com o mesmo líquido extrator e por outro lado, a extração com água corrente de frações de bagaço com menores teores de sólidos solúveis. No esgotamento ou lavagem do bagaço foram testados diferentes volumes de água deionizada iniciais representados pela razão água (volume) : bagaço (massa) especificamente no experimento $\mathbf{A}$ sendo testada a razão 0,6:1, no $\mathbf{B}$ a razão 1:1 e no $\mathbf{C}$ a 2:1. Após homogeneização do bagaço com o líquido extrator (água), foi prensado e a «água de primeira lavagem» foi adicionada a um segundo «lote de bagaço» com a mesma massa do primeiro e a operação foi repetida até a obtenção do extrato de um terceiro lote.

\section{O tempo de maceração}

O efeito do tempo de maceração foi analisado para o primeiro lote de bagaço com o experimento $\mathbf{A}$ de água inicial com 1, 2, 5 e 10 horas; após a prensagem a água de lavagem foi adicionada em um segundo lote de bagaço onde também permaneceu 1, 2, 5 e 10 horas. Após cada tratamento foi realizada uma prensagem e avaliado o rendimento em volume e sólidos solúveis ( ${ }^{\circ}$ Brix).

\section{O número de lotes de bagaço}

O esgotamento do bagaço em relação ao número de lotes foi analisado com o experimento $\mathbf{B}$ de volume de água por peso de bagaço.

\section{O extrato para a produção de álcool}

$\mathrm{O}$ bagaço foi pesado e dividido em três partes iguais (lotes) designados de bagaço 1, 2 e 3 (Figura 1). Foi adicionada água na proporção do experimento $\mathbf{B}$ ao bagaço 1 ficando em repouso por 15 minutos, prensado e o extrato foi adicionado ao bagaço 2, que permaneceu em repouso pelo mesmo período de tempo e prensado sob as mesmas condições. Semelhantemente, o extrato do bagaço 2 foi adicionado ao bagaço 3 , e tratado sob as mesmas condições.

\section{A concentração de fibras}

Após a obtenção da água de lavagem, um novo volume de água foi adicionado ao bagaço 1 e o processo descrito acima foi repetido. Este procedimento foi repetido até o bagaço 1 apresentar teor de sólidos solúveis totais próximo a $1^{\circ}$ Brix, escolhido como critério de ponto de parada.

\section{Análises físico-químicas}

As técnicas analíticas utilizadas para açúcares redutores, açúcares redutores totais, compostos fenólicos, acidez total, nitrogênio total, cinzas, matéria seca, lipídeos foram descritas por IAL (1976) e Tanner \& Brunner (1985). O teor de cálcio e fósforo foram avaliados segundo Silva (1981). O magnésio e o potássio foram determinados de acordo com Malavolta et al. (1989). A determinação de fibra bruta foi realizada mediante o método de Weender (ASCAR, 1985). Todas essas análises foram efetuadas em triplicatas.

\section{RESULTADOS E DISCUSSÃO}

\section{$O$ volume do líquido extrator}

$\mathrm{Na}$ Tabela 1, pode ser observado que o volume de água utilizado no experimento $\mathbf{A}$ apresentou uma rápida concentração de açúcares ao final da segunda lavagem (10,5 ${ }^{\circ}$ Brix) e manteve-se estável após o terceiro lote de bagaço, com rendimento de $84 \%$. Os volumes superiores, experimento $\mathbf{B}$ e $\mathbf{C}$, apresentaram ao final do terceiro lote de bagaço um valor de 9 e $7^{\circ}$ Brix que corresponde a 69 e $53 \%$, respectivamente, de rendimento em relação ao suco de maçã, ou seja, para alcançar o volume de Brix próximo ao do suco, os extratos do bagaço 3 devem passar por uma concentração, o que pode ser inviável sob o ponto de vista econômico do processo.

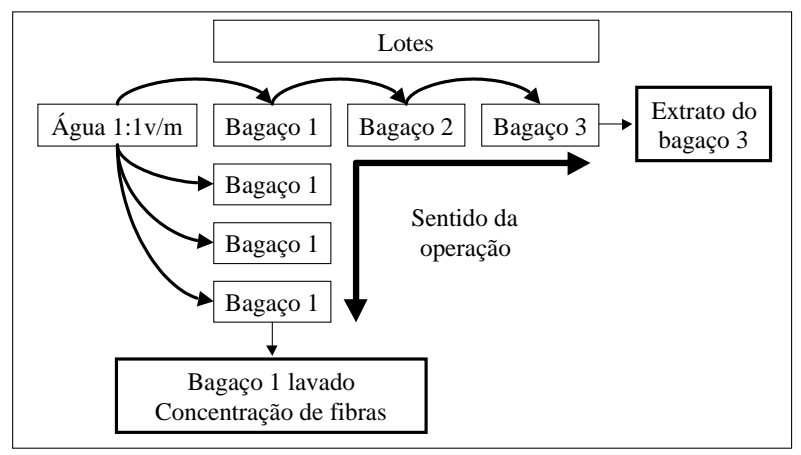

FIGURA 1 - Esquema do esgotamento do bagaço de maçã para a produção de álcool e concentração de fibras. 
TABELA 1 - Efeito do volume de água, durante a lavagem do bagaço, no rendimento em graus brix.

\begin{tabular}{cccccc}
\hline \multirow{2}{*}{$\begin{array}{c}\text { Experimento e razão } \\
\text { volume/massa }\end{array}$} & \multicolumn{3}{c}{ Extrato $\left({ }^{\mathbf{o}}\right.$ BRIX) } & \multirow{2}{*}{$\begin{array}{c}{ }^{\circ} \text { Brix do suco } \\
\text { de maçã }\end{array}$} \\
\cline { 2 - 4 } & Bagaço (1) & Bagaço (2) & Bagaço (3) & 13,0 \\
A & $0,6: 1$ & 7,5 & 10,5 & 11,0 & 13,0 \\
B & $1: 1$ & 5,0 & 8,0 & 9,0 & 13,0 \\
C & $2: 1$ & 3,0 & 5,0 & 7,0 & \\
\hline
\end{tabular}

\section{O tempo de maceração}

O efeito do tempo de maceração pode ser observado na Tabela 2. Os tempos de maceração 5 e 10 horas, no primeiro lote de bagaço, apresentaram um rendimento de 18 e $28 \%$ em volume de extração com $1,5^{\circ}$ Brix a mais em relação aos tempos de 1 e 2 horas. Ao segundo lote de bagaço adicionouse o extrato do primeiro lote e manteve-se os tempos de maceração. Com 2 horas de maceração foi alcançado o máximo de rendimento em Brix em todos os casos.

\section{Análises fisico-químicas}

As análises fisico-químicas do suco de maçã e dos extratos de lavagens do $1^{\circ}$ e $2^{\circ}$ lote de bagaço estão apresentadas na Tabela 3 e é possível observar que existiu um aumento expressivo de rendimento do primeiro para o segundo lote. Entretanto, os valores de acidez e cinzas diminuiram ( 80 e $77 \%$ respectivamente) no segundo extrato embora os valores de açúcares redutores totais alcançaram $100 \%$ de rendimento na extração do segundo lote. Os valores de magnésio também aumentaram em relação aos seus teores no suco, principalmente no extrato do $2^{\circ}$ lote, para as variedades Belgolden (4,78 para 9,78\%) e Fuji (6,85 para $10,30 \%)$. Os teores de nitrogênio, fósforo, cálcio e potássio não apresentaram diferenças importantes das concentrações encontradas no suco de maçã. Dessa forma, o extrato da segunda lavagem constituiu um meio apropriado para realizar uma fermentação alcoólica, sem necessidade de correções nutricionais.

\section{O número de lotes de bagaço}

$\mathrm{Na}$ Figura 2, pode ser observado que o rendimento de $80 \%$ foi alcançado nas primeiras 3 lavagens e continuando o processo o ganho foi de $1^{\circ}$ Brix até o $6^{\circ}$ lote, sendo que as lavagens sucessivas não apresentaram resultado em virtude de uma saturação do extrato. Assim, na razão do experimento $\mathbf{B}$ o processo pode ser conduzido até o terceiro lote.
TABELA 2 - Efeito do tempo de maceração no rendimento em graus brix, (Experimento $\mathbf{A}$ ).

\begin{tabular}{|c|c|c|c|c|c|}
\hline $\begin{array}{c}\text { Tempo } \\
\text { (h) }\end{array}$ & ${ }^{\circ}$ Brix & $\begin{array}{c}\text { Rendimento } \\
(\mathrm{mL})\end{array}$ & $\begin{array}{l}\text { Tempo } \\
\text { (h) }\end{array}$ & ${ }^{\circ}$ Brix & $\begin{array}{l}\text { Ganho } \\
{ }^{\mathbf{0}} \text { Brix }\end{array}$ \\
\hline \multirow{4}{*}{1} & \multirow{4}{*}{8,5} & \multirow{4}{*}{520} & 1 & 10,4 & 1,9 \\
\hline & & & 2 & 12,7 & 4,2 \\
\hline & & & 5 & 12,9 & 4,4 \\
\hline & & & 10 & 13,0 & 4,5 \\
\hline \multirow{4}{*}{2} & \multirow{4}{*}{8,5} & \multirow{4}{*}{420} & 1 & 12,4 & 3,9 \\
\hline & & & 2 & 12,6 & 4,1 \\
\hline & & & 5 & 12,1 & 3,6 \\
\hline & & & 10 & 13,1 & 4,6 \\
\hline \multirow{4}{*}{5} & \multirow{4}{*}{9,5} & \multirow{4}{*}{615} & 1 & 12,5 & 3,0 \\
\hline & & & 2 & 13,3 & 3,8 \\
\hline & & & 5 & 12,5 & 3,0 \\
\hline & & & 10 & 14,0 & 4,5 \\
\hline \multirow{4}{*}{10} & \multirow{4}{*}{9,4} & \multirow{4}{*}{670} & 1 & 12,6 & 3,2 \\
\hline & & & 2 & 13,2 & 3,8 \\
\hline & & & 5 & 13,5 & 4,1 \\
\hline & & & 10 & 13,5 & 4,1 \\
\hline
\end{tabular}

\section{A produção de álcool e concentração de fibras}

$\mathrm{Na}$ Tabela 4, dependendo do processo, o produto final pode ser um extrato para fermentação alcoólica (processo horizontal) ou para concentração de fibras (processo vertical) pelo esgotamento dos sólidos solúveis, constituindo um resíduo tratado para ser empregado na extração de pectinas ou para uso como volumoso na alimentação animal.

No processo horizontal, utilizando a razão do experimento $\mathbf{B}$ ao final do terceiro lote de bagaço, a água de lavagem apresenta um rendimento em volume de $160 \%$ com 79 g.L. $\mathrm{L}^{-1}$ de açúcares que podem ser transformados por fermentação alcoólica em 4,6 \% de álcool. Como o álcool de frutas tem um valor de mercado superior ao álcool de cana, a destilação deste fermentado torna-se uma fonte de renda para o pequeno, médio e grande produtor. 
TABELA 3 - Composição físico-química do suco de maçã e dos extratos da primeira e segunda lavagens em três variedades de maçã, com o experimento $\mathbf{A}$.

\begin{tabular}{|c|c|c|c|c|c|c|c|c|c|}
\hline \multirow[t]{2}{*}{ Análises } & \multicolumn{3}{|c|}{ Suco de maçã } & \multicolumn{3}{|c|}{$\begin{array}{c}\text { Extrato da primeira } \\
\text { lavagem } \\
\text { (1h de maceração) }\end{array}$} & \multicolumn{3}{|c|}{$\begin{array}{l}\text { Extrato da segunda } \\
\text { lavagem } \\
\text { (2h de maceração) }\end{array}$} \\
\hline & Belgolden & Gala & Fuji & Belgolden & Gala & Fuji & Belgolden & Gala & Fuji \\
\hline Acidez total, $\mathrm{g} / 100 \mathrm{~mL}$ & 0,26 & 0,27 & 0,23 & 0,03 & 0,04 & 0,05 & 0,04 & 0,05 & 0,06 \\
\hline ART $^{*}, g / 100 \mathrm{~mL}$ & 12,20 & 11,30 & 11,70 & 9,24 & 8,30 & 10,76 & 12,85 & 12,21 & 14,81 \\
\hline $\mathrm{ARS}^{* *}, \mathrm{~g} / 100 \mathrm{~mL}$ & 11,18 & 8,52 & 11,23 & 5,39 & 5,19 & 6,92 & 7,66 & 7,19 & 8,48 \\
\hline${ }^{\circ}$ Brix & 12,30 & 12,20 & 14,00 & 7,50 & 7,20 & 8,50 & 9,70 & 10,00 & 12,00 \\
\hline Cálcio, mg/L & 12,74 & 13,68 & 13,25 & 6,07 & 13,13 & 10,96 & 10,78 & 14,99 & 11,18 \\
\hline Cinzas, g/100mL & 0,51 & 0,50 & 0,66 & 0,11 & 0,16 & 0,24 & 0,11 & 0,19 & 0,08 \\
\hline Fósforo, mg/L & 22,46 & 27,11 & 32,19 & 30,54 & 24,32 & 32,33 & 27,76 & 36,66 & 34,85 \\
\hline Magnésio, mg/L & 4,78 & 6,20 & 6,85 & 5,93 & 4,49 & 3,64 & 9,78 & 5,17 & 10,30 \\
\hline Nitrogênio, g/100mL & 0,01 & 0,01 & 0,01 & 0,01 & 0,01 & 0,01 & 0,01 & 0,02 & 0,01 \\
\hline $\mathrm{pH}$ & 4,18 & 4,33 & 4,26 & 5,23 & 5,24 & 5,13 & 5,34 & 5,29 & 5,11 \\
\hline Potássio, mg/L & 2047 & 2457 & 2628 & 1102 & 1203 & 1613 & 1530 & 1946 & 1809 \\
\hline
\end{tabular}

*ART: açúcar redutor total ; **ARS: açúcar redutor solúvel.

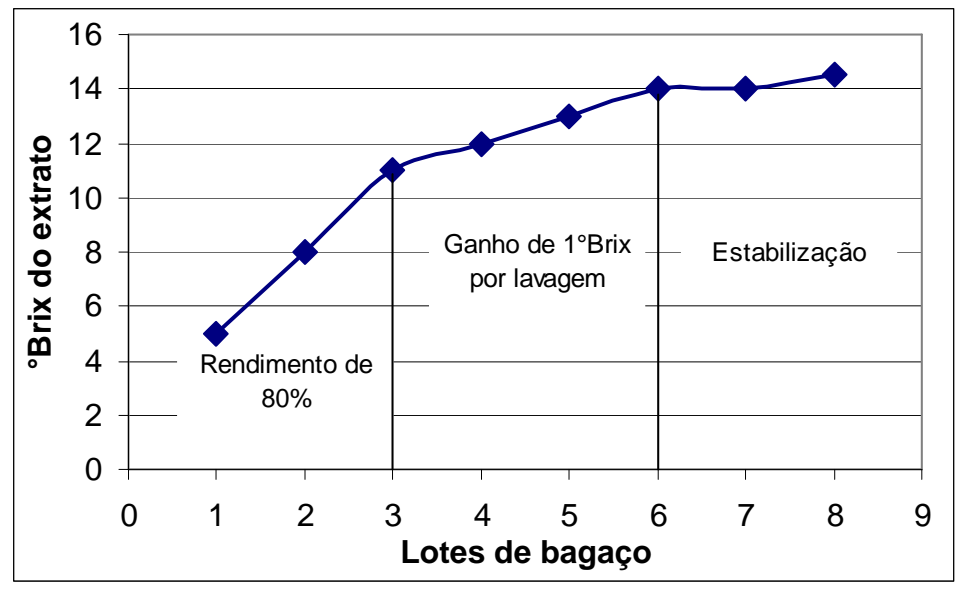

FIGURA 2 - Efeito da lavagem sobre o número de lotes de bagaço, com o experimento B.

No processo vertical, após 4 lavagens, os sólidos solúveis do primeiro lote foram retirados na quase totalidade pelo processo de difusão. No segundo lote foram necessárias 6 lavagens, sempre utilizando a água de extração do primeiro lote. Este processo de esgotamento do bagaço agrega valor ao resíduo como alimento para ruminantes ou para uma indústria de extração de pectina (Tabela 4). 
TABELA 4 - Extração de sólidos solúveis do bagaço de maçã por lavagem com o volume de água do experimento B com a finalidade de produzir álcool ou concentrar fibras ou extração de pectina.

\begin{tabular}{|c|c|c|c|c|c|c|}
\hline \multirow[t]{11}{*}{$\begin{array}{l}\text { Sentido da } \\
\text { operação }\end{array}$} & \multicolumn{6}{|c|}{ PRODUÇÃO DE ÁLCOOL } \\
\hline & \multirow{2}{*}{ Lavagens } & \multirow{2}{*}{ Parâmetros } & \multicolumn{3}{|c|}{ Bagaco } & \multirow{2}{*}{ Extrato final } \\
\hline & & & 1 & 2 & 3 & \\
\hline & & Peso bagaço, g & 550 & 550 & 550 & \\
\hline & 10 & Volume, $\mathrm{mL}$ & 725 & 830 & 880 & Análises do \\
\hline & 1 & Graus Brix & 6,0 & 8,0 & 9,0 & extrato 3 \\
\hline & & Sólidos totais, $\mathrm{g} / \mathrm{L}$ & 43,5 & 66,4 & 79,2 & (Tab. 5) \\
\hline & & $\%$ de alcool & 2,56 & 3,91 & 4,66 & \\
\hline & & Peso bagaço, $\mathrm{g}$ & 385 & 415 & 460 & \\
\hline & o & Volume, mL & 450 & 440 & 490 & \\
\hline & $2^{2}$ & Graus Brix & 3,5 & 6,0 & 7,5 & n.a. \\
\hline \multirow{22}{*}{ 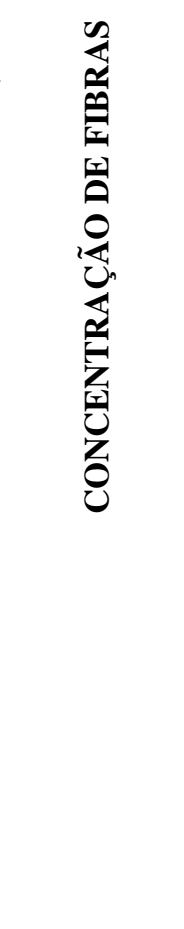 } & & Sólidos totais, $\mathrm{g} / \mathrm{L}$ & 15,75 & 26,4 & 36,75 & \\
\hline & & $\%$ de alcool & 0,93 & 1,55 & 2,16 & \\
\hline & & Peso bagaço, g & 280 & 400 & 380 & \\
\hline & 20 & Volume, $\mathrm{mL}$ & 250 & 320 & 360 & \\
\hline & $3^{\circ}$ & Graus Brix & 2,5 & 5,0 & 6,5 & n.a. \\
\hline & & Sólidos totais, $\mathrm{g} / \mathrm{L}$ & 6,25 & 16,0 & 23,4 & \\
\hline & & $\%$ de alcool & 0,37 & 0,94 & 1,37 & \\
\hline & & Peso bagaço, g & 300 & 330 & 300 & \\
\hline & 40 & Volume, mL & 330 & 330 & 320 & \\
\hline & 4 & Graus Brix & 1,5 & 3,5 & 5,0 & n.a. \\
\hline & & Sólidos totais, g/L & 4,95 & 11,55 & 16,0 & \\
\hline & & $\%$ de alcool & 0,29 & 0,68 & 0,94 & \\
\hline & & Peso bagaço, g & 210 & 250 & 270 & \\
\hline & 50 & Volume, mL & & 240 & 230 & \\
\hline & $5^{\circ}$ & Graus Brix & Análise do & 2,0 & 3,5 & n.a. \\
\hline & & Sólidos totais, g/L & bagaço 1 & 4,8 & 8,05 & \\
\hline & & $\%$ de alcool & (1 abela 5) & 0,28 & 0,47 & \\
\hline & & Peso bagaço, g & & 220 & 250 & \\
\hline & 60 & Volume, mL & & 200 & 190 & \\
\hline & $6^{\circ}$ & Graus Brix & n.a. & 1,5 & 3,0 & n.a. \\
\hline & & Sólidos totais, $\mathrm{g} / \mathrm{L}$ & & 3,0 & 5,7 & \\
\hline & & $\%$ de alcool & & 0,18 & 0,34 & \\
\hline
\end{tabular}

Nota: n.a. = não analisado.

As principais diferenças entre o bagaço e o bagaço tratado, observadas na Tabela 5, são os teores de açúcares que diminuiram de 2,58 g/100 g para 0,34 g/100 g, as fibras brutas que aumentaram de 8,76 para $20,04 \mathrm{~g} / 100 \mathrm{~g}$ e o teor de acidez que diminuiu de 0,092 para $0,053 \mathrm{~g} / 100 \mathrm{~g}$. Os valores do suco de maçã em comparação com o extrato da terceiralavagem, demonstrou um rendimento de $70 \%$ em sólidos solúveis.
Pode ser observado uma diminuição do teor de acidez de 0,253 para $0,159 \mathrm{~g} / 100 \mathrm{~g}$ e em compostos fenólicos em cerca de 250 ppm. Os compostos nitrogenados não apresentaram diferenças entre o suco de maçã e o extrato o que pode favorecer a fermentação alcoólica. Porém, a operação de sulfitagem é necessária uma vez que o pH aumentou para 4,06 o que eleva o risco de contaminações microbianas. 
TABELA 5 - Composição físico-químicas do bagaço inicial e lavado e do suco de maçã e do extrato da lavagem.

\begin{tabular}{lcccc}
\hline \multicolumn{1}{c}{ Análises, g/100g } & Bagaço inicial & Bagaço lavado & Suco de maçã & Extrato da lavagem \\
\hline Açucar redutor soluvel & 2,58 & 0,34 & 10,37 & 7,53 \\
Cinzas & 1,52 & 1,72 & - & - \\
Acidez & 0,09 & 0,05 & 0,27 & 0,16 \\
Umidade & 1,63 & 1,49 & - & - \\
Matéria Seca & 88,2 & 93,41 & - & - \\
Fibra bruta & 8,76 & 20,04 & - & - \\
pH* & - & - & 3,83 & 4,06 \\
Graus Brix & - & - & 13,50 & 9,50 \\
Açucar redutor total & - & - & 13,89 & 10,14 \\
Fenois totais (mg/L) & - & - & 501 & 228 \\
Nitrogênio $(\mathrm{mg} / \mathrm{L})$ & - & - & 169 & 167 \\
\hline
\end{tabular}

Nota: (-) não analisado. * adimensional

Numa abordagem quantitativa, com este trabalho, demonstra-se que a partir de 1 tonelada de bagaço de maçã, na razão do experimento $\mathbf{B}$, será possível produzir 720 litros de extrato a $20^{\circ}$ Brix, ou seja, superior a 1 tonelada de canade-açúcar que produz 600 litros a $20^{\circ}$ Brix (CRISPIN \& VIEIRA, 2001). Além disso, de 50.000 toneladas de bagaço, considerando-se um rendimento não-otimizado de $15 \%$ de pectina alimentícia, podem ser obtidas 7.500 toneladas de um produto com elevado valor agregado e que inexiste no mercado brasileiro (CANTERI-SCHEMIN et al., 2005). Com cautela estuda-se ainda otimizar o processo de extração ácida de pectina a partir de farinha de bagaço de maçã que pode chegar a valores superiores a $20 \%$.

Assim, demonstra-se duas formas de agregar valor ao bagaço de maçã, de baixo custo e com benefícios generalizados para pequenas, médias e grandes indústrias, que diferem entre si apenas no capital empregado.

\section{CONCLUSÃO}

a) Com menor volume de água no processo de extração ocorreu um aumento na concentração de nutrientes incluindo açúcares no extrato, com um volume final pequeno.

b) $\mathrm{O}$ tempo de maceração acima de 5 horas acarretou um maior rendimento em volume no primeiro lote e no segundo lote, com 2 horas de maceração foram obtidos os maiores rendimentos em açúcares.

c) A maior extração de sólidos solúveis foi alcançada nas primeiras 3 lavagens; nas seguintes o aumento de sólidos solúveis foi de $1^{\circ}$ Brix por extração.

d) $\mathrm{O}$ extrato do bagaço apresentou um elevado teor de açúcares e nutrientes, o que o torna propício para a fermentação alcoólica, com interesse especial para pequenos produtores.

e)Com 1 tonelada de bagaço de maçã, na razão 1:1 $\mathrm{v} / \mathrm{m}$, será possível produzir 720 litros de mosto a $20^{\circ}$ Brix.

f)Quatro extrações com água foram suficientes para exaurir os açúcares do bagaço.

\section{AGRADECIMENTOS}

Os autores são profundamente agradecidos à Universidade Estadual de Ponta Grossa, especialmente ao Departamento de Engenharia de Alimentos, onde os experimentos foram desenvolvidos, ao CNPq que forneceu as bolsas de IC, RD e Produtividade em Pesquisa que subsidiam e ativam o trabalho dos pesquisadores, e este é mais um artigo produzido sob a égide do grupo de trabalho sobre maçã -GTM.

\section{REFERÊNCIAS BIBLIOGRÁFICAS}

ALMOSNINO, A. M.; BELIN, J. M. Apple pomace: an enzyme system for producing aroma compounds from polyunsaturated fatty acids. Biotechnology Letters, Dordrecht, v. 13, n. 12, p. 893-898, 1991.

ASCAR, J. M. Alimentos: aspectos bromatológicos e legais: análise percentual. São Leopoldo: [s.n.], 1985. v. 1, $327 \mathrm{p}$.

ASSOCIAÇÃO BRASILEIRA DE PRODUTORES DE MAÇÃ. Dados estatísticos sobre a cultura da macieira.

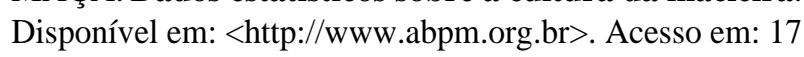
set. 2003. 
BEROVIC, M.; OSTROVERSNIK, H. Production of Aspergillus niger pectolytic enzymes by solid state bioprocessing of apple pomace. Journal of Biotechnology, Amsterdam, v. 53, n. 1, p. 47-53, 1997.

CANTERI-SCHEMIN, M. H.; FERTONANI, H. C. R.; WOSIACKI, G.; WASZCZYNSKYJ, N. Extraction of pectin from apple pomace. Brazilian Archives of Biology and Technology, Curitiba, v. 48, n. 2, p. 259-266, 2005.

CHEN, H.; RUBENTHALER, G. L.; SCHANUS, E. G. Effect of apple fiber and cellulose on the physical properties of wheat flour. Journal of Food Science, Chicago, v. 53, n. 1, p. 304-305, 1988.

CRISPIN, J. E.; VIEIRA, S. A. Cana de açúcar: boa altenativa agrícola e energética para a agricultura nacional. 2001. Disponível em: <wwww.epagri.com.bri 2003.

DOWNING, D. L. Apple cider. In: . Processed apple products. New York: Van Nostrand Reinhold, 1989. p. 169-187.

GLUNK, U. Increasing the juice yield of processing: with special remarks on the water extraction of apples. Flüssiges Obst, Schönborn, v. 48, n. 8, p. 235-237, 1981.

HANG, Y. D. Production of fuels and chemicals from apple pomace. Food Technology, Chicago, v. 41, n. 3, p. 115-117, 1987.

INSTITUTO ADOLFO LUTZ. Métodos físicos e químicos para análise de alimentos. In: 3. ed. São Paulo, 1976. Normas analíticas.

JEWELL, W. J.; CUMMINGS, R. J. Apple pomace energy and solids recovery. Journal of Food Science, Chicago, v. 49, n. 2, p. 407-410, 1984.

KENNEDY, M.; LIST, D.; LU, Y.; FOO, L. Y. Apple pomace and products derived from apple pomace: uses, composition and analysis. In: Modern methods of plant analyses: analysis of plant waste materials. Berlin: Springer Verlag, 1999. p. 75-119.

MALAVOLTA, E.; VITTI, G. C.; OLIVEIRA, S. A. Avaliação do estado nutricional das plantas: princípios e aplicações. Piracicaba: ABPPF, 1989. 201 p.

NGADI, M. O.; CORREIA, L. R. Solid state ethanol fermentation of apple pomace as affected by moisture and bioreactor mixing speed. Journal of Food Science, Chicago, n. 3, p. 667-670, 1992.

PAGANINI, C.; NOGUEIRA, A.; DENARDI, F.; WOSIACKI, G. Análise da aptidão industrial de seis cultivares de maçãs, considerando suas avaliações físico-químicas: dados da safra 2001/2002. Ciência e Agrotecnologia, Lavras, v. 28, n. 6, p. 1336-1343, 2004.

SILVA, D. J. Análise de alimentos: métodos químicos e biológicos. Viçosa: UFV, 1981. 166 p.

STURZA, R. C. M. C. Aproveitamento biotecnológico dos resíduos provenientes da extração do suco de maçã por fermentação no estado sólido. 1995. 81 f. Dissertação (Mestrado em Tecnologia Química) - Universidade Federal do Paraná, Curitiba, 1995.

TANNER, H.; BRUNNER, H. R. Getränke anlytik: untersuchungsmethode für dia labor: und betriebspraxis. Wädesnwill: Verlag Helles, 1985. 206 p.

VILLAS-BOAS, S. G.; ESPOSITO, E. Bioconversão do bagaço de maçã. Biotecnologia - Ciência \& Desenvolvimento, Brasília, p. 38-42, 2001.

WOSIACKI, G.; NOGUEIRA, A.; SILVA, N. C. Brazilian apple production: a fews years later. Fruit Processing, Chicago, v. 12, p. 472-475, 2000. 